\title{
Ekstraksi dan Analisis Produk di Marketplace Secara Otomatis dengan Memanfaatkan Teknologi Web Crawling
}

\author{
http://dx.doi.org/10.28932/jutisi.v5i3.1977
}

\author{
Edward Hanafi Fernando ${ }^{\# 1}$, Hetthroh Sagala ${ }^{* 2}$, Ariel Elbert Budiman ${ }^{\# 3}$, \\ Ivan Nathaniel Husada ${ }^{\# 4}$, Hapnes Toba ${ }^{\circledR \# 5}$ \\ "Program Studi Magister Ilmu Komputer, Fakultas Teknologi Informasi \\ Universitas Kristen Maranatha \\ Jl. Prof. drg. Surya Sumantri No.65 Bandung \\ ${ }^{1}$ mi1879004@student.it.maranatha.edu \\ 2mi1879014@student.it.maranatha.edu \\ ${ }^{3}$ mi1879009@student.it.maranatha.edu \\ ${ }^{4}$ mi1879008@student.it.maranatha.edu \\ ${ }^{5}$ hapnestobalit.maranatha.edu
}

\begin{abstract}
Along with the advancement in technology, today's community begins to abandon conventional shopping methods where buyers must come to the seller's shop. Nowadays the community mostly doing online shopping because the process is considered more convenience. Because of this, there are more and more online marketplace users. Much more data can be retrieved with the increasing number of online marketplace users. Because of the large amount of data, the process for extracting the data so that it can be seen and utilized becomes possible. The purpose of this study is to show data and extraction methods from an online marketplace system so that the results can be visualized and users can analyze the data. The data extraction methods that will be used are web crawling and web scraping where after the data is successfully extracted and cleaned it will be visualized with the Power BI application. The experiments show that the methods are useful to conduct analysis.
\end{abstract}

Keywords - data visualize; online marketplace; web crawling; web scraping.

\section{Pendahuluan}

Online Marketplace dewasa ini mengalami perkembangan yang sangat pesat. Dengan dukungan dari semakin pesatnya perkembangan dari mobile website diperkirakan online marketplace akan bertumbuh dengan cepat pada tahun-tahun mendatang [14]. Marketplace yang awalnya ada di forum forum online kini sudah memiliki sebuah sistem terpusat dimana para pengguna internet dapat memasukan data barang jualannya untuk nantinya akan dilihat oleh calon konsumen. Tidak hanya sebagai penyedia fitur untuk menemukan barang, online marketplace telah memiliki fitur pembayaran yang dapat melayani transaksi antara calon pembeli dengan para penjual. Perkembangan yang pesat ini menjadikan online marketplace salah satu alternatif yang menjadi favorit dalam melakukan transaksi jual beli baik bagi para penjual dan pembeli.

Selain informasi mengenai barang pada online marketplace sekarang ini menampilkan beberapa informasi seperti jumlah barang terjual, info mengenai kapan seorang penjual bergabung, ranking dari penjual level dari seorang penjual, rating, testimoni seorang penjual dan banyak lagi. Selain mengenai penjual pada online marketplace pun menyediakan informasi barang yang dijual oleh setiap penjual.

Melalui halaman-halaman pada online marketplace tersebut dapat mengumpulkan data - data untuk membentuk suatu informasi yang berguna. Namun untuk mengumpulkan variasi data tersebut bukanlah hal yang mudah. Banyaknya jumlah dari penjual dan ragam barang yang terdapat pada web tersebut menyebabkan kesulitan untuk mengumpulkan data yang diperlukan. Diperlukan sebuah cara atau sistem yang secara otomatis dapat mengumpulkan data dari setiap halaman yang menampilkan atau data yang disediakan pada halaman web tersebut.

Selain pengumpulan data, hal lain yang harus diperhatikan adalah makna data. Pada sebuah halaman data terdapat data yang cukup banyak. Agar data data tersebut dapat berguna, perlu dirancang sebuah tempat pengelolaan data dimana pada tempat tersebut variasi data akan disimpan. Data harus dipilih dan disusun dengan baik agar ketika penggunaan dapat memberi arti yang baik dan dapat menunjang di setiap kegiatan yang diperlukan. 


\section{KAJIAN LITERATUR}

Berdasarkan pada pernyataan diatas, maka pada riset ini membutuhkan beberapa metode dan tools dalam pengerjaannya. Metode yang digunakan adalah web scrapping, dan web crawling sementara tools yang digunakan adalah Scrappy, Splash, dan Power BI.

\section{A. Web Scraping}

Web Scraping disebut juga web harvesting, web data extraction atau web mining, yaitu kegiatan mengkonstruksi agen untuk mengunduh, mengurai, dan mengatur data dari halaman web secara otomatis. Hal ini dimaksudkan kegiatan pengguna dalam mengambil data dari layar web dilakukan oleh web scraper dengan tujuan agar pengambilan data dapat dilakukan dengan lebih cepat dan lebih tepat.

Web crawler melintasi halaman-halaman web untuk diekstraksi oleh Web scraping. Saat pengambilan data dari halaman web, cukup sulit untuk menentukan halaman web yang cukup relevan. Dengan web crawler, pengunjungan halaman web dapat menggunakan local search algorithm untuk membatasi URL antara halaman web [3].

Dengan web scraping, pengguna dapat mengambil data data mentah yang ada di web page seperti tabel pada halaman Wikipedia, atau review sebuah film untuk melakukan text mining, daftar real - estate untuk geolocation, membangun data set dari penjualan atau forecasting, analisa jejaring sosial, atau bahkan memantau berita atau topik terbaru di internet.

Lalu bagaimana dengan API yang disediakan oleh web tertentu untuk memuat data yang ada pada website tersebut? Twitter dan Amazon adalah salah satu contoh web yang menyediakan layanan API dimana dapat mengakses API tersebut untuk mendapatkan data - data yang diperlukan. Namun pemanfaatan API memiliki beberapa kekurangan seperti [2] :

1. Tidak semua website memberikan fasilitas API.

2. Fasilitas API yang diberikan umumnya tidak gratis.

3. Penggunaan API tersebut dibatas umumnya seberapa sering pengguna dapat mengakses API tersebut.

4. API tidak memberikan data secara keseluruhan.

Sedangkan dengan menggunakan web scraping, apapun yang pengguna dapat lihat pada web browser dapat mengambil data tersebut kemudian menyimpan dan membersihkannya dengan baik.

\section{B. Web Crawling}

Web Crawling memiliki peran yang berbeda dengan web scraping kendati sama - sama digunakan pada halaman web. Sebuah web crawler bertugas untuk berpindah-pindah di antara halaman web secara otomatis selama web scraping bekerja. Crawling adalah aktifitas dalam membuat salinan dalam porsi yang relevan yang diambil dari sebuah World Wide Web[10] dan web crawling adalah tahap terpenting dalam pencarian informasi web[13]. Dalam membangun sebuah web crawler perlu memperhatikan beberapa hal yang dapat mempengaruhi cakupannya seperti Web crawler terbatas pada sebuah halaman yang sudah terstruktur dengan baik, dimana pengguna bisa tahu apa yang ada pada halaman tersebut [8].

Karena pengguna dan konten dari World Wide Web semakin meningkat dengan pesat sehingga dibutuhkan metode untuk mencari dan mengambil data dengan cepat [11]. Karena itu web crawling adalah metode yang penting untuk mengumpulkan data [12]. Terkadang diperlukan membuat tiruan dari halaman web supaya dapat mengambil data pada halaman tersebut. Kasus ini biasanya terjadi ketika berhadapan dengan halaman yang menggunakan javascript.

Membangun sebuah web crawler memerlukan perhatian khusus karena tidak menginginkan web crawler menemui jalan buntu atau proses yang sangat lama. Beberapa contoh hal yang perlu diperhatikan adalah harus mengetahui halaman - halaman web apa saja yang sudah dikunjungi sebelumnya, data apa saja yang ingin diambil, lalu bagaimana cara penyimpanan data tersebut. Berikut beberapa hal yang perlu diperhatikan dalam pembuatan web crawler:

1. Pastikan data yang akan diambil, apakah halaman tersebut memiliki data - data yang diperlukan.

2. Gunakan dataset, hal ini dapat dilakukan dengan menggunakan media penyimpanan data seperti database, jangan lupa memberikan penanda waktu pada data tersebut sehingga tahu apabila ada data baru yang masuk.

3. Pisahkan crawling dan scraping.

4. Apabila web crawler tidak menemukan data yang diinginkan setelah beberapa saat, ada baiknya untuk menghentikan proses.

5. Ketika terjadi kesalahan pada saat proses, perlu memperhatikan apa perlu untuk mencoba ulang proses atau mengakhirinya.

6. Perhatikan antrian saat melakukan proses crawling, jika melakukan proses terlalu cepat dapat menemukan kegagalan karena proses yang terlalu cepat. Taruh jeda waktu di antara antrian.

7. Perhatikan aspek legal ketika melakukan scraping. Beberapa situs tidak menginginkan halaman webnya dibombardir dengan banyaknya HTTP request.

\section{Scrapy}

Scrapy adalah sebuah web framework yang kuat untuk mengambil data dari berbagai sumber [9]. Sumber data yang dimaksud berupa situs web dan scrapy akan mengekstraksi data terstruktur yang dapat digunakan untuk berbagai aplikasi yang bermanfaat, seperti data mining, pemrosesan informasi atau arsip sejarah. Scrapy pada awalnya dirancang untuk melakukan web crawling tapi pada saat ini Scrapy 
juga dapat digunakan untuk mengekstraksi data menggunakan API (seperti Amazon Associates Web Services) atau sebagai web crawler dengan tujuan lainnya. Gambar 1 merupakan tampilan terminal dari penggunaan scrapy[5].

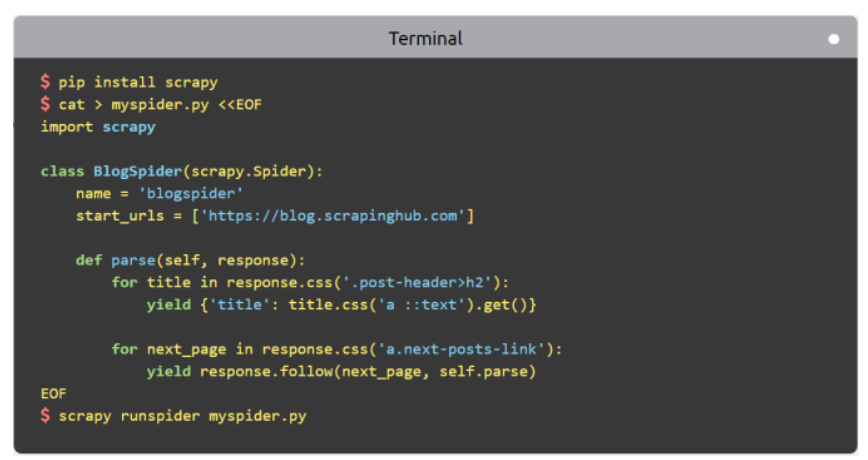

Gambar 1. Terminal dari Scrapy

\section{Splash}

Splash adalah layanan untuk melakukan rendering pada javascript website yang diimplementasikan dalam Python 3. Scrapy sebagai web crawler memiliki kelemahan ketika akan melakukan ekstraksi pada halaman web yang berbasis javascript. Hal ini disebabkan karena halaman pada web berbasis javascript atau ajax tidak mengunggah data secara keseluruhan sehingga menyebabkan scrapy mengekstrak data secara premature. Gambar 2 merupakan tampilan terminal dari Splash. Dan gambar 3 merupakan contoh hasil response dari penggunaan Splash [6].

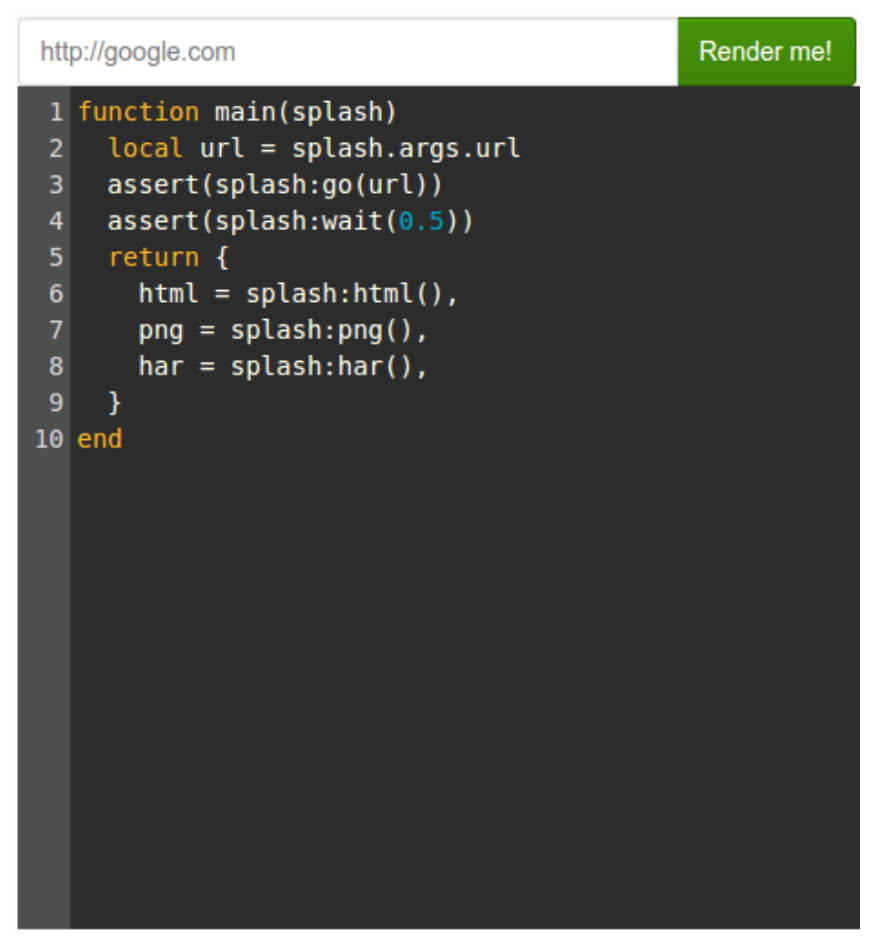

Gambar 2. Terminal dari Splash



Gambar 3. Contoh hasil response dari splash

Untuk mengatasi masalah ini splash akan digunakan sebagai perantara dalam proses memuat halaman web. Dalam prosesnya splash bertindak sebagai aplikasi yang memuat halaman web terlebih dahulu secara keseluruhan, kemudian web yang sudah dimuat tersebut akan di ekstrak oleh scrapy. Oleh karena itu, scrapy bisa mendapatkan data halam secara keseluruhan walaupun halaman web tersebut merupakan halaman web berbasis javascript.

\section{E. Power BI}

Power BI adalah kumpulan tools analisis bisnis dari Microsoft untuk menganalisis data dan membuat suatu insight dari data tersebut dalam bentuk suatu laporan dan dashboards. Data pengguna dalam berbagai bentuk seperti spreadsheet, file teks, database, dll adalah input untuk Power BI, lalu data ditransformasikan sesuai kebutuhan bisnis menjadi dataset. Setelah dataset siap, laporan bisa dibuat dengan cara memvisualisasikan dengan berbagai elemen yang disediakan oleh Power BI. Power BI juga menyediakan fitur Quick Insights dimana fitur ini menggunakan berbagai algoritma untuk menganalisis data dan membuatkan laporannya secara otomatis. Setelah laporan-laporan tersebut sudah selesai, dapat ditampilkan dalam suatu dashboards yang berisi berbagai informasiinformasi penting bagi penggunanya [1]. Gambar 4 merupakan contoh visualisasi data dengan Power BI [7].

Units by Product and Sale Size
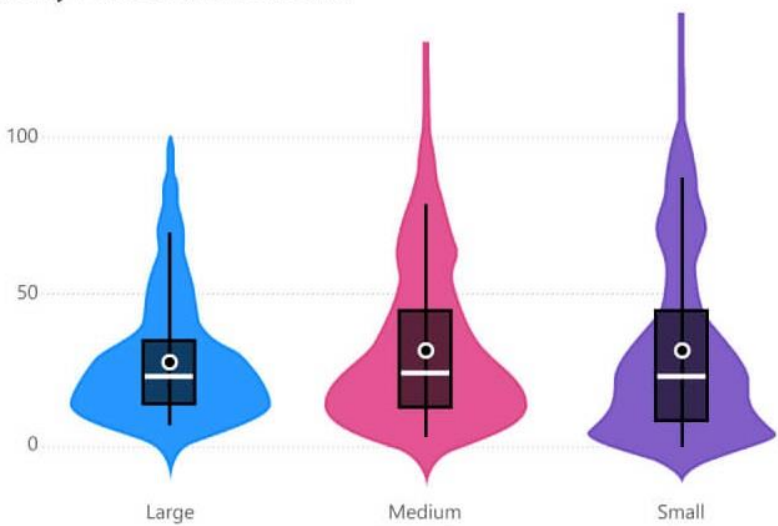

Gambar 4. Contoh Visualisasi Data dengan PowerBI 


\section{F. Data Analytics}

Data Analytics adalah ilmu tentang mengekstraksi nilai atau insight dari sebuah sumber data dimana data harus terlebih dahulu diproses sedemikian rupa sebelum menjadi insight yang berharga. Data Analytics sebagai dalam organisasi seringkali digambarkan sebagai alur kerja yang menggambarkan langkah-langkah yang harus dilakukan dalam proyek analisis data, baik itu pembangunan suatu model prediksi, seperti pelanggan mana yang bereaksi positif terhadap suatu kampanye pemasaran, segmentasi pelanggan, atau sekadar pembuatan otomatis laporan berkala yang mencantumkan beberapa statistik deskriptif [1]. Dalam proses analisis data, web scraping mempunyai peran dalam mengidentifikasi dan menyeleksi sumber data untuk digunakan dalam membuat suatu model. Dalam kasus tertentu, web scraping dapat menjadi komponen penting dalam proyek data analytics dimana saat diperlukan statistik dasar dan visualisasi dari hasil data scraping. Dalam web scraping perlu memperhatikan data quality, khususnya jika berurusan dengan World Wide Web, dimana banyak sekali data yang tidak terstruktur dan berantakan, sehingga diperlukan banyak sekali data cleaning dan fail-safe dalam program scraper yang dibuat.

\section{SUMBER DATA DAN METODOLOGI}

Metodologi Pengumpulan data akan dilakukan dengan membangun sebuah aplikasi yang mengimplementasikan metode web scraping dan web crawling. Dengan data dari marketplace "T" yang merupakan salah satu marketplace terbesar dan juga mempunyai user aktif terbanyak dan memakai input produk smartphone "g" sebagai input pencariannya diharapkan hasil data yang dapat diambil akan dapat divisualisasi sehingga hasil dari visualisasi tersebut akan dapat digunakan sebagai bahan penelitian untuk menentukan kota mana di Indonesia yang merupakan pasar terbesar dari produk smartphone "g" tersebut.

Gambar 5 menunjukan flowchart langkah kerja dimana proses penarikan data diawali dengan memuat web page marketplace dengan menggunakan splash. Setelah web page berhasil dimuat kemudian script python akan menarik data hasil render untuk disimpan ke dalam database. Sumber data untuk proyek kali ini akan diambil dari web online marketplace yang ada di Indonesia dengan kategori item smartphone merk tertentu.

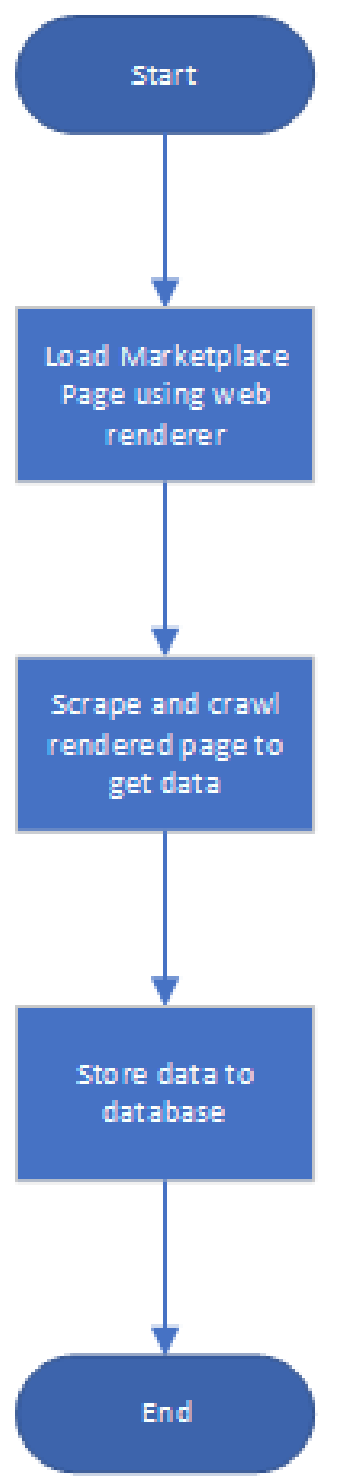

Gambar 5. Flowchart Langkah Kerja

\section{A. Marketplace " $t$ "}

Marketplace " $\mathrm{t}$ " adalah salah satu marketplace terbesar di Indonesia. Selain itu marketplace tersebut juga merupakan salah satu marketplace dimana masyarakat Indonesia banyak menggunakannya untuk transaksi barang dengan kategori Gadget. Diharapkan dengan dipilihnya marketplace tersebut sebagai sumber data, data yang diambil akan lebih valid dan lebih dapat dipercaya. Selain itu penulisanpenulisan dalam metode pencarian yang terdapat pada halaman marketplace tersebut juga dianggap lebih dapat dimengerti sehingga akan memberikan kenyaman dalam proses pengambilan data.

\section{B. Produk Smartphone " $g$ "}

Smartphone "g" adalah nama produk smartphone dengan banyak peminat. Produk-produk dari smartphone "g" 
memiliki variasi harga yang cukup luas dan variasi jenis

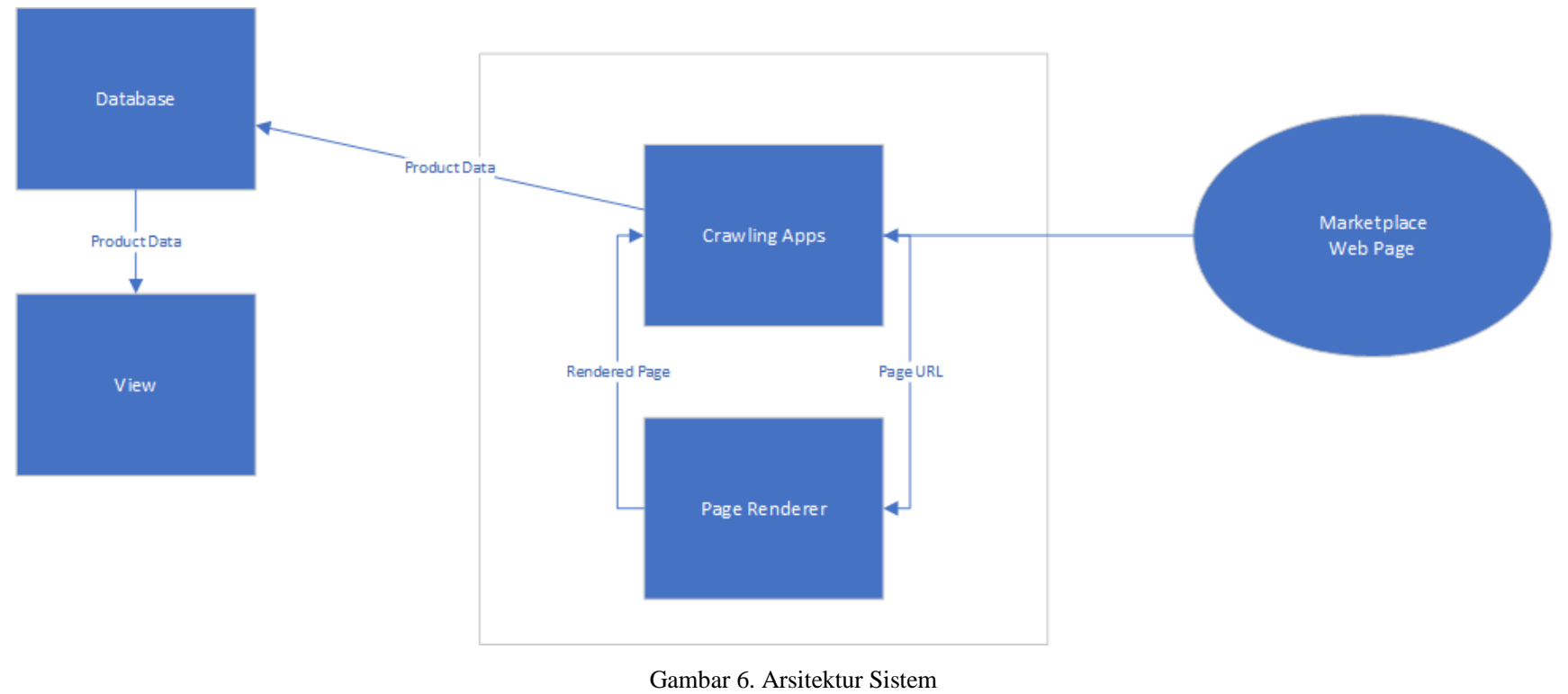

yang cukup banyak. Karena peminatnya cukup banyak lokasi penjual juga menjadi sangat variatif.

Gambar 6 menunjukan proses ekstrasi data dari web hingga menjadi sebuah grafik. Aplikasi akan melakukan render pada $U R L$ yang diberikan. Setelah $U R L$ berhasil di render kemudian data akan diproses dan diambil sesuai dengan kriteria yang sudah diatur sebelumnya. Setelah seluruh data pada URL selesai dilakukan data tersebut kemudian disimpan ke dalam penyimpanan basis data. Data yang sudah tersimpan ke dalam basis data kemudian akan ditampilkan melalui grafik chart sesuai dengan kriteria yang sudah ditentukan.

\section{Manipulasi IP}

Pada saat proses web crawling, user agent yang digunakan untuk web crawling ada kemungkinan diblokir oleh marketplace[4]. Berikut merupakan beberapa cara yang disarankan untuk mengantisipasi pemblokiran oleh marketplace :

1. Memanipulasi IP. IP proxy yang digunakan berbeda beda pada setiap user agent untuk menghindari pemblokiran IP. Terdapat beberapa IP Server yang menyediakan IP

2. Perlu memperhatikan berapa banyak request yang akan dilakukan untuk menghindari blok IP yang disebabkan terlalu banyaknya request pada satu waktu.

\section{ARSITEKTUR SISTEM}

Pada proyek ini data yang diambil berasal dari web marketplace online. Data pada marketplace online tersebut akan diambil dengan menggunakan python dengan memanfaatkan library scrapy dan splash. Sebelum data pada marketplace diambil, halaman web page marketplace di render terlebih dahulu menggunakan splash, hal ini diperlukan apabila halaman web marketplace tersebut merupakan halaman web berbasis javascript. Setelah di render kemudian data halaman web marketplace tersebut diambil datanya menggunakan scrapy. Data diambil berdasarkan tag HTML. Data yang diambil kemudian akan disimpan ke dalam database untuk dapat dipakai untuk membangun sebuah diagram.

1. Database - MySQL

Sebagai penyimpanan basis data dari hasil proses pengerjaan web crawling dan web scraping. Data yang sudah diambil akan disimpan di database MySQL sesuai dengan data-data yang sudah ditentukan.

2. Bahasa Pemrograman : Python, SQL

Sebagai bahasa penulisan program yang akan dipakai sebagai basis environment ketika menuliskan script web crawling dan web scraping dan juga bertugas untuk menjalankan program web crawling dan web scraping tersebut.

\section{Scrapy}

Framework yang dituliskan dengan menggunakan bahasa python, dimana framework ini akan menjadi kerangka kerja dalam pengerjaan proses pengambilan data dalam web crawling dan web scraping.

4. Splash

Digunakan sebagai perantara untuk merender situs dari halaman marketplace " $T$ " yang pada halaman marketplace tersebut menggunakan web dinamis dengan javascript sehingga untuk dapat melakukan pengambilan datanya sesuai dengan yang diinginkan dibutuhkan proses rendering terlebih dahulu. 


\section{Docker}

Layanan virtualisasi sebagai lokasi untuk melakukan instalasi dan menjalankan Splash.

6. PowerBI

Untuk melakukan visualisasi pada data yang sudah bersih sehingga data yang didapat dapat dianalisis sehingga menghasilkan suatu kesimpulan yang dapat dimanfaatkan untuk keperluan lainny

\section{RANCANGAN SISTEM}

Berikut merupakan rancangan database product pada Postgree:

\begin{tabular}{|l|}
\hline \multicolumn{1}{c|}{ Product } \\
\hline + product_brand: varchar \\
+ product_series: varchar \\
+ product_size: varchar \\
+ product_codename: varchar \\
+ currency: varchar \\
+ product_prize: varchar \\
+ store_city: varchar \\
+ store_name: varchar
\end{tabular}

Gambar 7. Database Produk

Gambar 7 berisi data data diambil dari marketplace yang telah ditentukan. Rincian atribut sebagai berikut :

1. Product Brand: Merk dari produk sesuai dengan input nama merk produk smartphone dari penjual yang menjual barangnya di marketplace.

2. Product Series: Jenis seri dari produk sesuai dengan input sesuai jenis produk smartphone yang diinputkan oleh penjual yang menjual barangnya di marketplace

3. Product Size: Ukuran besarnya memory dari produk smartphone yang dijual oleh penjual di marketplace.

4. Product Codename: Tipe dari produk smartphone yang dijual oleh penjual di marketplace sesuai dengan jenis smartphone yang dijual.

5. Currency: Mata uang yang digunakan sebagai alat pembayaran yang akan digunakan di dalam Marketplace untuk dipakai dalam membeli produk smartphone yang dijual oleh penjual di marketplace tersebut.

6. Product Price: Harga dari produk smartphone yang sesuai dengan input nama produk dari penjual yang menjual barangnya di marketplace.

7. Store City: Lokasi dari penjual smartphone pada marketplace.

8. Store Name: Nama toko dari penjual smartphone di marketplace.

\section{HASIL IMPLEMENTASI SISTEM}

Web crawling dan web scraping dilakukan pada situs online marketplace. Web scraper bertugas untuk mengambil data data produk dari hasil pencarian di situs tersebut, sedangkan web crawler bertugas untuk berpindah antar halaman pencarian secara otomatis.

Web crawler \& web scraping dibangun dengan menggunakan bahasa pemrograman Python, dan menggunakan library scrapy serta splash.

Scrapy adalah library Python yang memiliki fungsi utama dalam proses ekstraksi data dari halaman web dengan menyertakan url dari halaman web yang akan di ekstrak. Scrapy melakukan ekstrak data berdasarkan dari tag html yang ada di dalam halaman web. Untuk itu perlu menganalisa apa saja tag yang diperlukan untuk diekstrak nilainya. Tag yang digunakan harus dalam bentuk css selector atau dalam bentuk xpath.

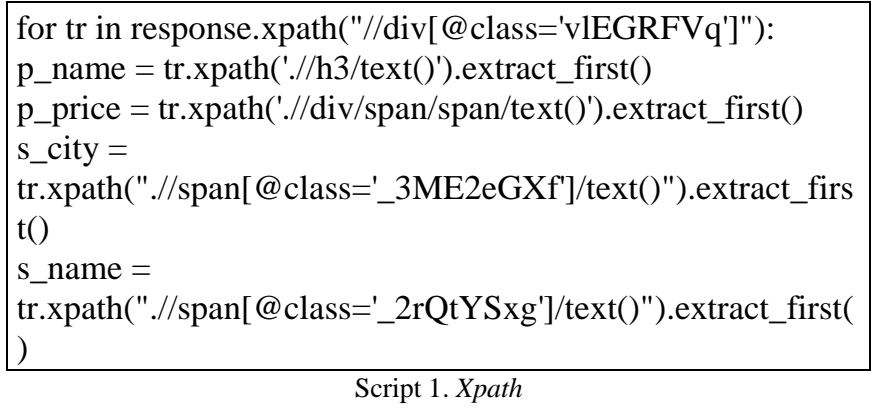

Pada for loop script 1 perulangan berjalan berdasarkan pada elemen $\mathrm{html}$ dengan kelas "vlEGRFVq" didapatkan dari inspect halaman HTML dan berulang berdasarkan jumlah elemen yang terdapat pada kelas tersebut yang. Untuk setiap perulangan program akan mengambil data berdasarkan path yang dimulai dari elemen html yang digunakan pada for loop. Kode extract.first() dimaksudkan agar aplikasi hanya mengambil nilai pertama saja karena terkadang terdapat lebih dari satu nilai yang dikembalikan.

Kelas Untuk halaman web yang berbasis javascript perlu menggunakan splash agar scrapy dapat melakukan ekstraksi secara keseluruhan. Ada lebih dari satu metode yang disediakan oleh splash dalam proses memuat situs sebelum siap digunakan atau siap diekstraksi oleh scrapy, salah satunya adalah splash: set_viewport_full(). Metode ini memerintahkan splash untuk memuat dulu web secara keseluruhan.

\footnotetext{
def start_requests(self):

url = 'https://www.t.com/search?st=product\&q=g' script $=" " ' "$

function main(splash, args) assert(splash:go(args.url)) assert(splash:wait(5)) splash:set_viewport_full() return \{
} 


\begin{tabular}{|l|l|}
$\begin{array}{l}\text { html }=\operatorname{splash}: \text { html(), } \\
\text { png = splash:png(), } \\
\text { har = splash:har(), } \\
\text { "'"' }\end{array}$ \\
Script 2. Splash
\end{tabular}

Script 2 merupakan script lua default untuk splash dengan beberapa modifikasi. Titik utama modifikasi terdapat "url pada = 'https://www.t.com/search?st=product\&q=g" di mana script ini menunjukan alamat web site yang akan diambil datanya. Kemudian yang perlu diperhatikan dalam modifikasi script ini adalah "splash:set_viewport_full()", script ini menjadi kunci utama dalam memuat halaman web secara keseluruhan terlebih dahulu baru kemudian proses pengambilan data dilakukan. Script ini ditujukan untuk mencegah proses pengambilan data terjadi prematur dikarenakan data belum dimuat secara keseluruhan.

Untuk proses crawling dapat membuatnya secara manual. Sebagai contoh pada riset ini proses crawler dengan memanfaatkan perulangan. Dalam proses ini proses perulangan dilakukan pada url pencarian dimana akan memodifikasi angka halaman hasil pencarian.

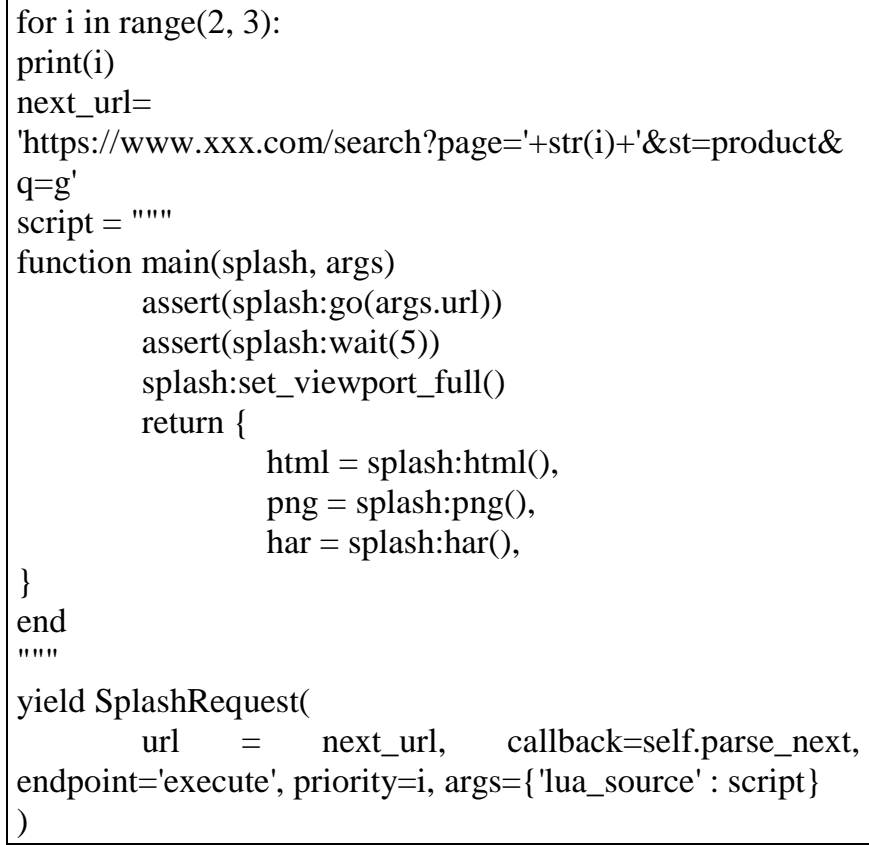

\section{Script 3. Splash}

Pada kode Script 3 perulangan untuk pengambilan data datur manual pada baris kode "for $\mathrm{i}$ in range $(2,3)$ :", dimana perulangan ini bermaksud mengulan mulai dari halaman 2 hingga halaman 3. Kemudian baris kode "next_url = 'https://www.t.com/search?page='+str(i)+'\&st=product\&q=g "' bertujuan menyimpan alamat web pada variable url.
Alamat web dibentuk secara dinamis berdasarkan halaman yang akan diambil datanya.

Dalam menjalankan program scrapy ini perlu diperhatikan beberapa pengaturan seperti pada gambar 8 agar program sesuai dengan beberapa aturan pada beberapa situs. Umumnya perlu memperhatikan aturan pada robot.txt yang ada pada sebuah situs.



Gambar 8. Aturan pada Robot.txt

Selain aturan pada file robots.txt yang disediakan oleh situs yang akan diekstrak, perlu juga memperhatikan berapa banyak halaman yang akan diproses dalam satu waktu. Hal ini untuk menghindari terlalu banyaknya http request yang dikirimkan pada situs yang dapat menyebabkan di ip di blok. Untuk mengatur hal ini pada scrapy dapat melakukanya dengan mengubah nilai dari CONCURRENT_REQUEST yang terdapat pada file settings seperti pada script 4 .

\section{CONCURRENT_REQUESTS $=1$ \\ Script 4. Pengaturan Scrappy}

Concurrent_request adalah pengaturan pada scrappy untuk membatasi berapa banyak pemanggilan yang akan di lakukan pada web marketplace yang dituju. Hal ini bertujuan agar tidak membebani web marketplace dan mencegah agar tidak terjadi blocking pada ip.

Setelah data diekstrak, data perlu disimpan ke dalam sebuah media penyimpanan. Sebagai media penyimpanan dapat menggunakan file dengan format $\operatorname{csv}$, json, atau 
sebuah database. Untuk mengatur tempat penyimpanan data dapat melakukanya pada file pipelines.

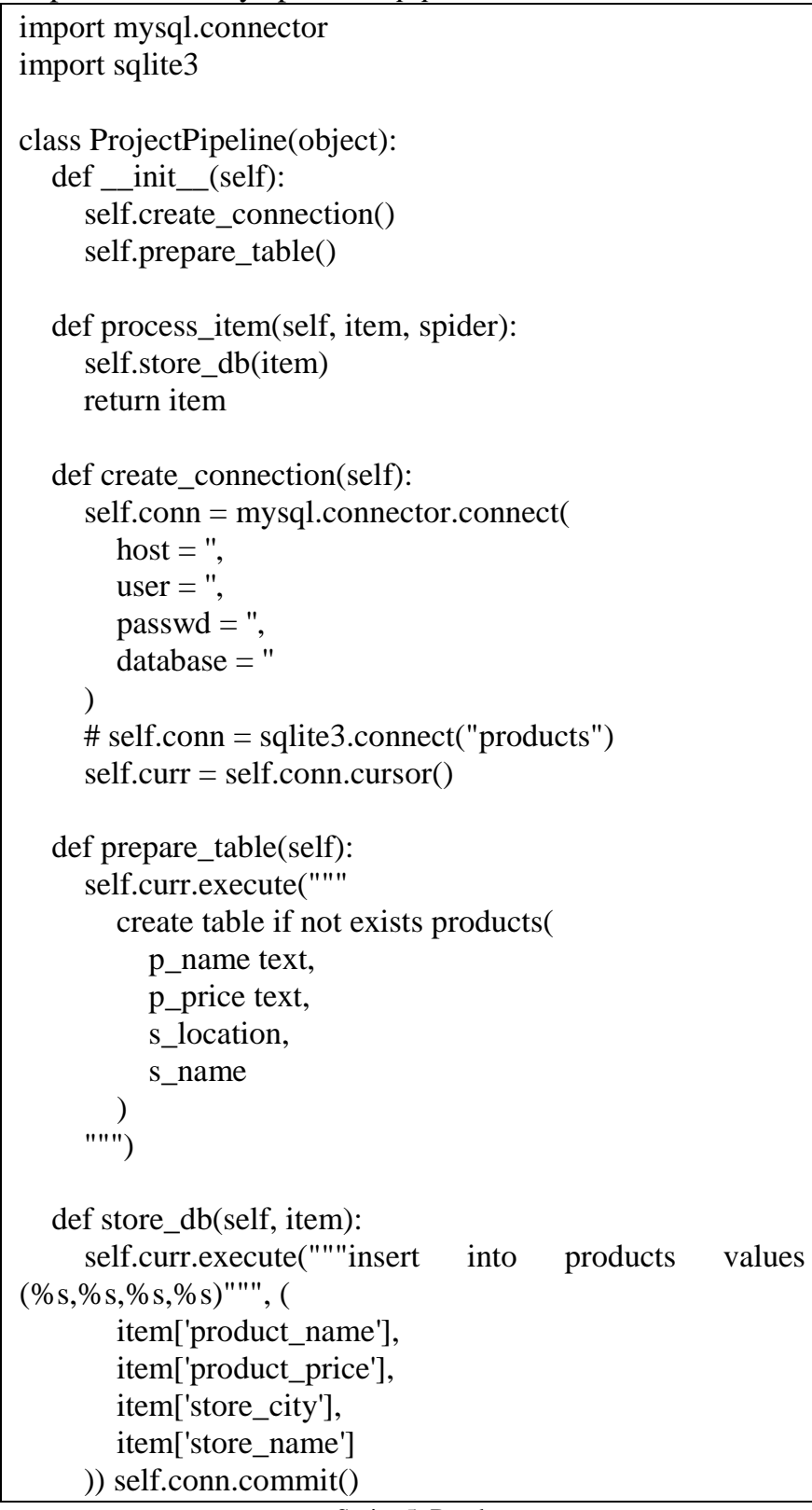

Script 5. Database

Script 5 diatas adalah kode untuk mempersiapkan database tempat data yang telah diambil disimpan. Kode pada "def init (self):" adalah kode untuk mempersiapkan koneksi database. "self.create_connection()" berfungsi untuk membuat koneksi ke database, "self.prepare table()" berfungsi untuk mempersiapkan tabel


process item(self, item, spider):" adalah fungsi yang dipanggil untuk menyimpan data ke dalam database dengan menggunakan fungsi "self.store_db(item)". Fungsi "def prepare_table(self):" adalah fungsi yang digunakan untuk membuat tabel tempat menyimpan data yang sudah diambil apabila tabel belum tersedia dengan menggunakan kode "self.curr.execute" dengan parameter query sql. Fungsi "def store_db(self, item):" digunakan untuk menyimpan data ke dalam database dengan menggunakan kode self.curr.execute dengan parameter sql.

\section{HASIL EKSPERIMEN DAN EVALUASI}

\section{A. Ekstraksi Produk}

Script Scrapy dengan class spiders akan dijalankan menggunakan jupyter notebook console berdasarkan kata kunci yang ditentukan. Splash akan menjadi perantara antara marketplace dengan website dinamis dengan pengguna yang akan melakukan proses crawling dan scraping pada website marketplace tersebut sehingga data yang telah ditentukan sebelumnya akan dapat diambil dan hasilnya akan sesuai dengan data yang sudah ditentukan sebelumnya. Proses akan dijalankan sampai semua data yang ditentukan berhasil diambil sesuai dengan hasil pencarian untuk barang yang sudah ditentukan sebelumnya dari halaman pertama hingga terakhir.

019-06-23 15:52:32 [scrapy,core,scraper] DEBUG: Scraped from $<200$ https://www.t.com/search?page $=3 \&$ s

\{'currency': 'rp',

'product_brand': 's',

'product_codename': 'g',

'product_price': '433.000',

'product_series': 'xs',

'product_size': '120',

'store city': 'Jakarta' \}

s g tab a 102019 sm-t515 32gb - black

[s, g, tab, a, 10, 2019, sm, t515, 32, gb, -, black]

019-06-23 15:52:32 [scrapy,core,scraper] DEBUG: Scraped from $<200$ https://www.t.com/search?page $=3 \& \mathrm{~s}$

\{'currency': 'rp',

'product_brand': 's',

'product_codename': 'g',

'product_price': '4.750.000',

'product_series': 'xs', 
'product_size': '32',

'store city': 'Medan'\}

s g s10 s 10 ume classic flip case cover leather

[s, g, slO, s, 10, ume, classic, flip, case, cover, leather]

019-06-23 15:52:32 [scrapy,core,scraper] DEBUG: Scraped from $<200 \mathrm{https}: / /$ www.t.com/search?page=3\&s

$\{$ 'currency': 'rp',

'product_brand': 's',

'product_codename': 'g',

'product_price': '50.000',

'product_series': 'xs',

'product_size': '32',

'store city': 'Jakarta'\}

S g s10 s 10 case soft anti crack casing jelly bening

[s, g, slO, s, 10, case, soft, anti, crack, casing, jelly, bening] Script 6. Hasil Web Scraping

Berdasarkan hasil pada Script 6, Web Scraping berhasil dilakukan dan mendapatkan data yang sudah dipisahkan berdasarkan: product_name, product_price, store_city, store_name. Data tersebut langsung dimasukan ke dalam database.

B. Analisis Data

Data yang sudah dibersihkan akan divisualisasi menggunakan power $B I$. Berikut merupakan hasil visualisasi dari power $B I$.

\begin{tabular}{lr} 
Tocation & Count of price \\
\hline Jakarta & 292 \\
Surabaya & 45 \\
Bandung & 29 \\
Medan & 23 \\
\hline Batam & 16 \\
Malang & 6 \\
Tangerang & 6 \\
Kab Bandung & 5 \\
Kab Tangerang & 5 \\
\hline Jambi & 4 \\
\hline Gambar 9. Total Penjul Berdasarkan Lokas
\end{tabular}

Gambar 9. Total Penjual Berdasarkan Lokasi



Gambar 10 Pie Chart Penjualan Berdasarkan Lokasi

Berdasarkan Gambar 9 dan Gambar 10 dapat disimpulkan bahwa penjual dari kota Jakarta merupakan penjual terbanyak yang menjual produk smartphone "g" pada marketplace " $T$ ". Berdasarkan data yang berhasil diambil, jumlah penjual smartphone " $\mathrm{g}$ " yang menjual barangnya di marketplace " $T$ " ada sebanyak 292 penjual. Berdasarkan data yang didapat juga dapat disimpulkan bahwa aktivitas penjualan dari smartphone " $\mathrm{g}$ " pada marketplace " $T$ " di kota Jakarta merupakan yang tertinggi di Indonesia. Selain itu dari data tersebut juga dapat disimpulkan bahwa peminat paling banyak dari smartphone "g" di Indonesia berasal dari kota Jakarta. Sedangkan kota Surabaya merupakan penjualan kedua terbesar yaitu 45 , namun perbedaannya cukup signifikan dengan jumlah penjual yang ada di kota Jakarta.

\section{Evaluasi}

Untuk proses web crawling dan web scraping sudah berhasil sesuai dengan yang diharapkan dan data yang disimpan juga sudah sesuai dengan data yang sudah ditentukan sebelumnya. Dalam pengerjaannya juga data sudah dapat divisualisasikan dengan menggunakan Power $B I$ sesuai dengan rencana awal. Dan hasil dari visualisasi juga sudah dapat sesuai dengan kesimpulan dari data keseluruhan yang didapat dari proses web crawling dan web scraping. Tetapi berdasarkan eksperimen yang dilakukan, hasil yang didapat menunjukan perbedaan yang cukup signifikan antara jumlah pengamatan terbanyak dan juga jumlah pengamatan yang terbanyak berikutnya.

\section{KESIMPULAN DAN SARAN}

Proses pengambilan data dengan sumber marketplace yang sudah ditentukan sebelumnya sudah berhasil, dan data yang disimpan pun sudah sesuai dengan yang diinginkan. Data yang diambil juga sudah berhasil dilakukan visualisasi sesuai dengan tujuan awal dari pengambilan data. 
Diharapkan untuk pengerjaan lebih lanjutnya akan dapat melakukan proses web scraping dengan masuk kedalam perhalamannya sehingga pemilihan dari data yang akan diambil diharapkan akan lebih komplit dibanding dengan daftar data yang dapat diambil dalam halaman perkategori item yang ditentukan sehingga hasil dari visualisasi pun akan lebih dapat bervariasi tergantung data mana yang akan dijadikan objek penelitian dan perbandingan.

\section{DAFTAR PUSTAKA}

[1] Krishnan, Vijay, Bharanidharan, S., Krishnamoorthy, G., "Research Data Analysis with Power BI," 11th International CALIBER, 2017, p. 212.

[2] D. Glez-Pen<a, A. Lourenco, H. Lopez-Fernandez, M. Reboiro-Jato, F. Fdez-Riverola, "Web scraping technologies in an API world," Briefings in Bioinformatics, pp. 1-10, Feb. 2013.

[3] P. Ayar, C. Sandip, "Efficient Focused Web Crawling Approach for Search Engine," International Journal of Computer Science and Mobile Computing, vol. 4, issue. 5, pp. 545-551, May. 2015.

[4] Seppe v. Broucke \& B. Baesens, Practical Web Scraping for Data Science Best Practices and Examples with Python, New York: Springer Nature-Apress, 2018.
[5] (2019) Scrapy website. [Online]. Tersedia: http://scrapy.org/

[6] (2019) Splash website. [Online]. Tersedia: http://blog.scrapinghub.com/

[7] (2019) PowerBi website [Online]. Tersedia: http://powerbi.microsoft.com/

[8] Olston, C. and Najork, M, "Web Crawling," Foundations and Trends® in Information Retrieval, vol. 4(3), pp. 175-246, Feb. 2010

[9] Kouzis-Loukas D., Learning Scrapy. Birmingham: Packt Publishing, 2016.

[10] Genovese, L., \& Geraci, F, "Web Crawling and Processing with Limited Resources for. Journal of Software," Journal of Software, vol. 7, pp. 300-316, May. 2018

[11] Vandana Shrivastava, "A Methodical Study of Web Crawler," Journal of Engineering Research and Application, vol. 8, pp. 01-08, Nov. 2018.

[12] Mini Singh Ahuja, Dr Jatinder Singh Bal, Varnica. "Web Crawler: Extracting the Web Data," International Journal of Computer Trends and Technology, vol. 13(3), pp. 132-137, Jul. 2014.

[13] Shubham Age, Tushar Indorkar, Shital Kokate and Manisha Shitole, "A Self Adaptive Semantic Focused Web Crawler," International Journal of Research In Science \& Engineering, Vol. 1(6), pp. 74-79, Nov. 2017.

[14] Hana Choi, Carl F. Mela. "Online Marketplace Advertising," International Choice Symposium, 2016. 